\title{
The Capsaicin Paradox: Pain Relief by an Algesic Agent
}

\author{
Gábor Jancsó*, Orsolya Oszlács and Péter Sántha
}

Department of Physiology, Faculty of Medicine, University of Szeged, Hungary

\begin{abstract}
Chemosensitive primary sensory neurones expressing the TRPV1 receptor, a molecular integrator of diverse noxious stimuli, play a fundamental role in the sensation of pain. Capsaicin, the archetypical ligand of the TRPV1 receptor, is one of the most painful chemical irritants, and its acute administration onto the skin and mucous membranes elicits severe pain. However, repeated or high-dose applications of capsaicin, and/or its administration through specific routes dramatically decreases the sensitivity of the innervated tissues to noxious chemical and heat stimuli. This review surveys the mechanisms of the antinociceptive, anti-inflammatory and anti-hyperalgesic effects of vanilloid agonists applied topically, or perineurally, or injected into the subarachnoid space in animal experiments and to put these data into a clinical perspective. The great body of available experimental evidence indicates that vanilloid agonists exert their antinociceptive actions through TRPV1 receptor-mediated selective neurotoxic/neurodegenerative effects directed against somatic and visceral C-fibre nociceptive primary afferent fibres. It is expected that vanilloid agonists will broaden the palette of analgesic drugs which do not cause addiction and tachyphylaxis.
\end{abstract}

Keywords: Analgesia, capsaicin, neurogenic inflammation, pain, pain management, primary sensory neurone, spinal cord, TRPV1.

\section{INTRODUCTION}

Systematic studies on the regulation of the function of the reticulo-endothelial system by histamine and on the mechanisms of histamine desensitization led Nicholaus (Miklós) Jancsó to the recognition of the unique pharmacological properties of capsaicin and related pungent compounds. In his pioneering investigations, he elegantly demonstrated that repeated applications of capsaicin, the pungent ingredient of the capsicum species, selectively abolished the chemical pain sensitivity of the sensory nerve endings of the skin, mucous membranes and viscera [1-3]. The capsaicin-induced desensitization of the chemosensitive nerve terminals produced not only an impairment of their afferent functions, causing chemoanalgesia and the abolition of protective reflexes, but also inhibition of the sensory nerve-mediated inflammatory reactions, including local vasodilatation (hyperaemia) and increased microvascular permeability (plasma protein extravasation and oedema formation), generally referred to as neurogenic inflammation $[1,3,4]$. The abolition of the protective reflexes (e.g. in the eye wipe test) clearly indicated the development of capsaicin-induced analgesia, which rendered the animals unresponsive towards the pain-producing effects of capsaicin and other exogenous and endogenous chemical irritants. It was concluded that (repeated) topical applications of capsaicin cause a long-lasting (but frequently reversible) inhibition of both the sensory afferent and the local vascular "sensory efferent" functions [4,5] of a population of sensory nerves. It was apparent from this early stage of the research, however, that the action of capsaicin is highly selective for these "capsaicin-sensitive" elements of the peripheral nervous

*Address correspondence to this author at the H-6720, Szeged, Dóm tér 10, Hungary; Tel: 00-36-62-545101; 00-36-62-545099; Fax: 00-36-62-545842; E-mail: jancso@phys.szote.u-szeged.hu system, since neither the (low-threshold) mechanosensitive afferents conveying tactile sensation, nor the autonomic or somatomotor efferent nerves were affected. These observations provided the first selective pharmacological tool with which to study the contribution of the chemosensitive nerves to the afferent and local regulatory efferent functions of the sensory fibres [6]. Although the use of capsaicin became a powerful procedure for study of the physiological and pharmacological significance of chemosensitive nerve fibres in various biological processes, the identity of the primary sensory neurones affected by the actions of capsaicin remained largely unknown. Early electrophysiological studies demonstrated that the chemosensitive afferents activated by capsaicin belong among the unmyelinated $\mathrm{C}$-fibre population of peripheral nerves responsive to noxious chemical stimuli, but not to innocuous mechanical stimuli [7]. These features of the capsaicin-sensitive nerves satisfy the classical criteria of nociceptors as originally formulated by Sherrington. However, apart from their functional traits, the capsaicin-sensitive afferents remained anatomically indistinguishable from other afferent and autonomic efferent $\mathrm{C}$-fibres present in mixed peripheral nerves. Moreover, the somata of these nociceptors, which intermingle with other primary sensory neurones that convey different modalities in the spinal and cranial sensory ganglia, were also undistinguishable. The observation that the systemic administration of capsaicin to newborn animals (rats or, mice) produces a long-lasting (irreversible) elimination of chemosensitive small diameter C-fibre primary sensory neurones, rendering the animals unresponsive to capsaicin and other chemical stimuli, was therefore a significant step in the study of the mechanisms of nociception and pain [8]. These important observations on the neurotoxic effects of capsaicin and related vanilloids [9] were later extended considerably by studies which demonstrated that capsaicin can produce similar, though from certain aspects limited, neurotoxic and/or neurodegenerative effects within the 
population of chemosensitive primary sensory neurones depending on the site and dose of application and the type of vanilloid compound used. Detection of the morphological and neurochemical signs (i.e. the depletion of specific neurochemical markers) of the capsaicin-induced selective neurodegeneration and study of the consequences of this chronic chemodenervation provided a useful approach to the identification of capsaicin-sensitive structures in both the peripheral and the central nervous system, and to the detection of their contribution to a large variety of physiological and pathophysiological processes $[10,11]$. Importantly, this approach led to the identification of specific neuropeptides which mediate the neurogenic inflammatory response [12,13] and are involved in the transmission of pain. This approach had undoubtedly certain limitations, which were later partially overcome by identification of the specific capsaicin-binding site in the sensory neurones, the vanilloid type 1 transient receptor potential receptor (TRPV1) protein $[14,15]$ and the generation of TRPV1 knock-out transgenic mice [16,17]. A substantial body of evidence is now available, indicating that the capsaicin sensitivity of the chemosensitive primary sensory neurones is conferred exclusively by this non-selective, "polymodal" ion channel, which is the prototype of "sensory TRP" receptors and is the first and best-characterized archetypical nociceptor-specific molecular transducer identified in the peripheral nervous system [18]. Nevertheless, apart from being (and remaining) powerful experimental tools in sensory physiology and pharmacology, capsaicin and the related vanilloids (and other TRPV1 agonists) have also a significant therapeutic potential, which is probably neither adequately recognized nor effectively exploited at present.

In this review, we briefly summarize the morphological and functional consequences of capsaicin-induced neurodegeneration by comparing the different types/routes of capsaicin application. We also survey the current knowledge on the cellular mechanisms of vanilloid-induced neurotoxicity, and highlight the benefits and possible complications of the analgesia elicited by perineural/topical applications of capsaicin and related vanilloids. We hope that this information, may be of help in the recognition of vanilloid-induced analgesia as a valuable option for the management of painful conditions, and will promote translation of this method into medical practice.

\section{Acute and Chronic Effects of High-Dose Capsaicin: Neo- natal, Adult, Perineural and Intrathecal Administrations}

We first briefly discuss the consequences of the selective neurotoxic effects of the administration of capsaicin to newborn animals, which produces the most profound morphological and functional changes in, and affects the total population of capsaicin-sensitive primary sensory neurones. In this section, we focus primarily on the changes produced by capsaicin in the cutaneous and deep tissue nociceptors (Fig. 1). Neurotoxic changes affecting the capsaicin-sensitive visceral afferents and their possible therapeutic implications will be discussed separately.

\section{Neonatal Capsaicin Treatment}

Systemic (subcutaneous) administration of capsaicin (50 $\mathrm{mg} / \mathrm{kg}$ b.w.) to newborn animals (rats, mice and dogs) produces a long-lasting (irreversible) ablation of small-diameter
C-fibre primary sensory neurones [8,19-22], rendering the animals unresponsive to capsaicin and other exogenous (and endogenous) algogenic agents and chemical irritants. Capsaicin administration during the most sensitive 1-14-days postnatal period gives rise to a selective degeneration of primary sensory neurones in the spinal and cranial sensory ganglia and leads to a selective argyrophilic degeneration of spinal and cranial primary afferents through a unique, chemically induced primary centrifugal degeneration described by Cajal $[8,23,24]$. It reduces the number of (sensory) $\mathrm{C}$-fibres in both the peripheral nerve trunks and the spinal dorsal roots [8,24-26], and the density of sensory nerves in both the skin and the viscera. In the central nervous system, it affects the central terminals of the primary chemosensitive afferents, causing a robust degeneration of presynaptic axons and boutons in the superficial dorsal horn of the spinal cord, the marginal and caudalis subnuclei of the trigeminal nucleus, the nucleus of the solitari tract and the area postrema [23]. More recent publications have confirmed the practically complete overlap between these central nervous regions affected by capsaicin-induced argyrophilic degeneration and the localization of the TRPV1-expressing sensory nerve terminals visualized by immuno-histochemistry [27]. Quantitative data indicate that approximately $50 \%$ of the DRG neurons, $70 \%$ of the C-fibre afferents in the cutaneous nerves and up to $95 \%$ of $\mathrm{C}$-fibre dorsal root fibres in the rat are affected and later eliminated after neonatal treatment $[8,24,25]$.

The development of these degenerative morphological changes induced by capsaicin is rapid: ultrastructural changes in the dorsal root ganglion neurones can be observed after less than 30 minutes, in the peripheral nerves and dorsal roots after 4 hours [23] and in the spinal cord dorsal horn (Rexed's lamina I and II) after 6-12 hours [28]. The structural changes are preceded by biochemical changes, such as the intracellular accumulation of $\mathrm{Ca}^{2+}$, as shown in vivo by Jancsó et al., and activation of proteolytic enzymes [29,30]. Even more surprising is the fact, that the overt signs of degeneration in the perikarya and the central/peripheral axons/terminals disappear remarkably quickly: degenerating neurones in the DRG and axon terminals in the spinal dorsal horn are practically absent 24 hours after the injection of capsaicin. The rapid clearance of the cellular/axonal debris during about 3 days after the treatment is a consequence of the activation, migration and phagocytic activity of resident glial cells (microglia) and possibly other phagocytotic cells [28].

Because of the age-dependent technical limitations, assessment of the sensory function in neonates may be complicated, but it seems that the functional consequences of neonatal capsaicin treatment develop rather quickly after capsaicin treatment. The sensory deficit includes chemoanalgesia towards noxious chemical stimuli exerted by capsaicin and related compounds, as expressed by the decrease or complete extinction of behavioural responses or protective reflexes [8]. It has been demonstrated that the most characteristic functional deficit in TRPV1 knock-out animals is the decrease in thermal hyperalgesia elicited by the acute (nonneurogenic) inflammation. It is expected that thermal hyperalgesia should also be suppressed in capsaicin-induced chemical knock-outs. 


\section{The in vivo effects of capsaicin and other vanilloids upon different routes of applications}

\begin{tabular}{|c|c|c|}
\hline Type of treatment & Acute changes & Chronic changes \\
\hline Neonatal systemic & $\begin{array}{l}\mathrm{Ca}^{2+} \text { accumulation } \\
\text { Degenerative changes in the } \\
\text { perikaryon ( } 50 \% \text { DRG neurones) } \\
\text { Mitochondrial swelling } \\
\text { Central terminal degeneration } \\
\text { Degeneration of unmyelinated axons } \\
\text { (dorsal roots and peripheral nerves) } \\
\text { AP conduction block } \\
\text { Axoplasmatic transport block }\end{array}$ & $\begin{array}{l}\text { Loss of B-type sensory neurons } \\
\text { Loss of C fibres and nerve endings } \\
\text { Depletion of sensory neuropeptides and } \\
\text { markers } \\
\text { Sprouting of myelinated afferents } \\
\text { Chemo- and thermal analgesia } \\
\text { Loss of thermal hyperalgesia } \\
\text { Loss of neurogenic inflammation } \\
\text { Decreased visceral reflex afferent functions }\end{array}$ \\
\hline Adult s & $\begin{array}{l}\mathrm{Ca}^{2+} \text { accumulation } \\
\text { Degenerative changes in the } \\
\text { perikaryon }(\sim 15 \% \text { DRG neurones) } \\
\text { Mitochondrial swelling } \\
\text { Central terminal degeneration } \\
\text { AP conduction block } \\
\text { Axoplasmatic transport block }\end{array}$ & $\begin{array}{l}\text { Loss of some B-type sesnory neurones } \\
\text { Loss of C-fibres and nerve endings } \\
\text { Depletion of sensory neuropeptides and } \\
\text { markers } \\
\text { Chemoanalgesia } \\
\text { Decreased visceral reflex afferent functions }\end{array}$ \\
\hline Local & $\begin{array}{l}\text { Degenerative changes in the } \\
\text { peripheral C-fibres (terminals) } \\
\text { AP initiation/conduction block } \\
\text { Axoplasmatic transport block (?) }\end{array}$ & $\begin{array}{l}\text { Chemoanalgesia } \\
\text { Loss of thermal hyperalgesia } \\
\text { Depletion of peripheral nerve endings } \\
\text { Depletion of sensory neuropeptides and } \\
\text { markers from the periphery } \\
\text { Loss of neurogenic inflammation } \\
\text { Decreased visceral reflex afferent functions } \\
\text { (e.g. bladder) }\end{array}$ \\
\hline $\begin{array}{l}\text { Intrathe } \\
\text { cisterna }\end{array}$ & $\begin{array}{l}\text { Central terminal degeneration } \\
\text { AP conduction block } \\
\text { Axoplasmatic transport block (?) } \\
\text { Chemoanalgesia } \\
\text { Mechanical allodynia }\end{array}$ & $\begin{array}{l}\text { Chemoanalgesia } \\
\text { Loss of heat hyperalgesia (?) } \\
\text { Depletion of sensory neuropeptides and } \\
\text { markers from the spinal cord } \\
\text { Intact cutaneous neurogenic inflammation }\end{array}$ \\
\hline $\begin{array}{l}\text { Perine } \\
\text { applica }\end{array}$ & $\begin{array}{l}\text { Degenerative changes in the } \\
\text { peripheral C-fibres } \\
\text { Glial reaction } \\
\text { AP conduction block } \\
\text { Axoplasmatic transport block }\end{array}$ & $\begin{array}{l}\text { Depletion of peripheral axons and nerve } \\
\text { endings } \\
\text { Loss of some B-type neurones } \\
\text { Depletion of sensory neuropeptides and } \\
\text { markers (phenotypic switch) } \\
\text { Transganglionic degeneration } \\
\text { Chemo- and thermal analgesia } \\
\text { Loss of thermal hyperalgesia } \\
\text { Loss of neurogenic inflammation } \\
\text { Decreased visceral reflex afferent functions }\end{array}$ \\
\hline
\end{tabular}

Fig. (1). Domains of primary sensory neurons labelled in black and gray denote the occurance of unequivocal morphological signs of degeneration or changes in the chemical phenotype, e.g. depletion of peptides from the affected neurones.

Neonatal treatment with capsaicin results in practically complete abolition of the neurogenic inflammatory response $[8,13,24]$. The elimination of neurogenic plasma extravasation and vasodilatation elicited by chemical irritants (mustard oil, xylene or capsaicin) or antidromic electrical stimulation of sensory nerves has been demonstrated in the skin and different visceral organs (trachea, ureter and gut). It should additionally be noted that the inflammatory reactions induced by vasoactive agents such as histamine, bradykinin and serotonin are also significantly decreased, indicating a sensory nerve-mediated amplification of acute inflammatory reactions [24,31-33]. Neurogenic vasodilatation mediated by vasoactive peptides released from activated nerve terminals is also suppressed in the skin [12] and gastrointestinal tract [34]. Some observations suggest that the presumed trophic effects of the chemosensitive primary sensory neurones too are impaired, which might explain the development of skin lesions on the face, disturbed hair growth and corneal lesions observed after longer survival $[35,36]$.
Since the large majority of the chemosensitive primary sensory neurones are polymodal i.e. heat nociceptors, it is not suprising that the sensitivity towards other physical stimuli, such as noxius heat, is also decreased in these animals. The sensory threshold for noxious heat is significantly in creased as measured by various methods [37-39]. Finally, it must be emphasized that these morphological and functional changes (in the rat) seem to be irreversible, causing a lifelong reduction in the number of sensory neurones and axons and deficits in the sensory afferent and efferent functions of primary chemosensitive neurones $[10,11,18,40-42]$.

\section{Systemic Capsaicin Treatment of Adult Animals}

The systemic capsaicin treatment of adult rodents is generally referred to as capsaicin desensitization, for this treatment renders animals insensitive to capsaicin and other irritant chemicals. Functional and pharmacological desensitization are distinguished (the former is also known as defunctionalization) [43] to indicate that the treatment results in 
selective insensitivity to the action of capsaicin only, or in a general unresponsiveness of the animal to a variety of irritant chemicals. In other terms, pharmacological desensitization denotes the desensitization of the TRPV1 receptor, whereas defunctionalization results from action on other types of TRPs and nociceptive channels/receptors, such as ionotropic purinergic receptor $\mathrm{P} 2 \mathrm{X} 3$, proton channels (ASICs), bradykinin receptors, serotonergic receptors, prostaglandin and histamine receptors $[44,45]$. Defunctionalization may result from the sensory neurone blocking effect of capsaicin [4].

Although systemic capsaicin treatment of adult animals technically is equivalent to neonatal treatment (the dose is from $50-100 \mathrm{mg} / \mathrm{kg}$ to $300 \mathrm{mg} / \mathrm{kg}$ b.w. divided into fractions), the morphological and functional consequences on the primary sensory neurones are in general less pronounced. Possible explanation for the influence of the age and the developmental stage on capsaicin susceptibility will be discussed later. Early attempts to demonstrate morphological correlates for the capsaicin-induced functional deficits observed in adult animals revealed only limited ultrastructural changes in small dorsal root ganglion neurones [46]. Reinvestigation of the capsaicin-induced morphological changes in adult (more than 6 weeks old) rats and guinea pigs disclosed that about $17 \%$ of the lumbar dorsal root ganglion neurones exhibited clear-cut signs of degeneration as early as 1 hour after the injection of capsaicin [22,47]. Similarly to what was observed in neonates, the degenerating neurones exhibited increased cytoplasmic and nuclear basophilia, cytoplasmic vacuolization, shrinkage of the nucleus and chromatolysis. In addition, extensive argyrophilic degeneration of the synaptic boutons was seen in the superficial dorsal horn and trigeminal brain stem nuclei. Osmiophilic degeneration of a large population of unmyelynated C-fibres in the dorsal roots was apparent from electron microscopic studies. It was also found, that the systemic capsaicin treatment of adult rats produced depletion of the sensory neuronal marker enzyme fluoride-resistant acid phosphatase (FRAP) [48]. The reduction of other nociceptive neurone specific chemical markers, including substance P (SP), somatostatin (SOM) and isolectin B4 of Bandeira (Griffonia) simplicifolia (IB4) from the spinal dorsal horn is most probably caused by the degeneration of the central terminals of the peptidergic and non-peptidergic afferent neurones [49,50]. Reduction of the TRPV1 immunoreactivity was also recently observed in both the spinal cord and the sensory ganglia [51]. Although quantitative morphological data revealed a significant dosedependent loss of up to 50 per cent of the unmyelinated $\mathrm{C}$ fibres in peripheral nerves, this reduction was less than that observed after neonatal treatment [47]. It was therefore concluded that systemic capsaicin treatment in adult rats produces degeneration of only a subpopulation of capsaicinsensitive neurones. Peripheral terminals have also been reported to be affected following the systemic administration of capsaicin, which might explain the sensory deficits observed after such treatment [52-54].

Similarly to the morphological alterations the functional changes are less severe in adult animals. Although the nociceptive reflexes elicited by chemical irritants are impaired, there is only a moderate decrease in neurogenic plasma protein extravasation after a longer post-treatment period $[8,22,55]$.

\section{Localized Treatments with Capsaicin}

Although studies of the nociceptive and inflammatory phenomena in animals following systemic capsaicin injections have yielded important information on the mechanism(s) of pain and inflammation, selective blockade of the function of capsaicin-sensitive neurones serving a particular skin region or organ may be preferable for study of the functional significance of these particular nociceptive afferent nerves in targeted regions of tissues or organs. Systemic injections of capsaicin produce generalized initial excitation, which is followed by functional blockade and complete or partial degeneration of the whole system of capsaicinsensitive primary sensory neurones. Three possible application schemes have been developed and utilized for the selective desensitization or destruction of different domains of the capsaicin-sensitive neurone: local applications of capsaicin close to the termination sites of the peripheral axon terminals of sensory neurones (topical application); the direct application of capsaicin onto mixed peripheral nerve trunks (peri/epineural, intraneural or subepineural application); and the injection of capsaicin directly into the subarachnoid space, from where it rapidly reaches the central termination sites of the primary afferent axons (intrathecal and intracisternal applications).

\section{Topical Application}

The morphological and functional consequences of the topical application of capsaicin onto the skin, the mucous membranes or the luminal surfaces of different organs are dependent on a variety of factors, which may influence the penetration, distribution, absorption and finally the accessibility of the targeted neural elements (axon terminals) to capsaicin. These pharmacokinetic factors include the concentration of the drug, the lipo- or hydrophilic characteristics of the solvent and the application regime (single or repeated applications) and also the anatomical organization, circulation and barrier functions of the given organ/tissue. Since a huge variety of different types of treatments and locations have been targeted, we focus here on the most frequent and well-characterized applications of significant experimental and therapeutic value.

Epicutaneous capsaicin application is probably the most straightforward way to manipulate capsaicin-sensitive nerve endings terminating in the skin. The morphological properties of the tissue offer favourable conditions for the passive diffusion of lipophilic capsaicin preparations to reach the free nerve endings of the unmyelinated nociceptive axons which terminate in the most superficial layer of the epidermis. Indeed, capsaicin at a relatively low concentration activates the capsaicin-sensitive nerve endings in man, producing acute burning pain and thermal and tactile hyperalgesia. The redness/erythema which can also be observed at the site of or in the close vicinity of the application (flare response) is brought about by the release of vasoactive neuropeptides from the activated nerve endings [31,32]. In animal studies, the applications of capsaicin or similar chemical irritants onto the conjuctiva, which elicits characteristic protective reflexes (blepharospasm and eye-wiping), is also frequently used to assess the functional integrity of chemosensitive primary sensory neurones. Repeated epicutaneous or conjunctival application of capsaicin at concentrations of $>0.1 \%$ 
is known to result in the loss of chemogenic pain sensation, and cutaneous/conjunctival sensory neurogenic reactions. It is highly probable that at low concentrations capsaicin desensitization evolves at the receptorial level, producing the blockade of sensory transduction processes. There is convincing evidence that, at higher concentrations or after repeated applications of capsaicin, morphological changes occur, such as the (reversible) depletion of the intraepidermal free nerve endings [56,57]. After the application of capsaicin onto the skin, the loss and recovery of the nociceptive functions correlate with the degeneration and subsequent regeneration of intra-epidermal nerve endings [56]. Similar or even more robust morphological and functional changes are observed when capsaicin is injected subcutaneously [58]. It is difficult to define the diffusion limits of capsaicin following epicutaneous application, but it is possible that in the event of intracutaneous application, capsaicin can reach more proximal segments of the sensory axons, and give rise to a functional blockade and degenerative changes in these proximal axon segments, which might resemble the effects of perineural capsaicin treatment [59], as will be discussed later.

Some visceral organs also provide appropriate targets for therapeutic interventions through the use of capsaicin or other vanilloids locally to inhibit the activity of capsaicinsensitive nerves. The urinary bladder, which is accessible via moderately invasive application techniques, is a preferred organ, since the role of capsaicin-sensitive afferent nerves is well-established in the mechanisms of bladder inflammation and painful functional disturbances of micturition [60-65]. There is ample clinical evidence of the beneficial effects of intravesical capsaicin or resiniferatoxin in patients with hyperactive bladder disorders (overactive bladder, detrusor instability/overactivity or neurogenic bladder) or interstitial cystitis $[65,66]$. Intravesical application of capsaicin has been shown to decrease the pain elicited by bladder emptying and to enhance the compliance and the capacity of the bladder. Although such functional improvements ensue shortly after the treatment, there is a tendency to a relapse after longer periods of time, which can be prevented by repeated applications. This indicates that the functional and presumed morphological changes in visceral capsaicinsensitive sensory neurones are long-lasting, but reversible. Observations on the possible morphological changes are contradictory. Immunohistochemical studies indicated a reduction in the TRPV1-positive and the peptidergic nerve fibres in the epithelium and subepithelial layers of the bladder mucosa after topical capsaicin or resiniferatoxin treatment [67-70]. An ultrastructural study aimed at detection of vanilloid-induced morphological changes in the bladder sensory nerve endings failed to reveal any sign of axonal degeneration or damage after the intraluminal application of resiniferatoxin [69]. Other in vitro observations, however, indicated that, even at very low (submicromolar) concentrations capsaicin may induce severe osmiophilic degeneration of unmyelinated afferent axons in the guinea pig ureter [71].

\section{Administration of Capsaicin into the Subarachnoid Space: Intrathecal and Intracisternal Injections}

Injections of capsaicin into the subarachnoid space, either intrathecally [72-74] or intracisternally [75,76], have been utilized to activate and/or desenzitize the central terminals of capsaicin-sensitive primary sensory neurones. The rationale of this approach is that capsaicin injected into the cerebrospinal fluid can easily cross the liquor-brain barrier and reach the terminal segments and the terminals of primary afferent axons without affecting the soma and the peripheral axons of the $\mathrm{C}$-fibre sensory ganglion neurones. The intracisternal injection of capsaicin produces a prompt, but transient vasodilatation in the ear and protective eye and ear-wiping movements. These integrated nociceptive responses and the peripheral vasodilatation clearly indicate activation of the central spinal and trigeminal nociceptive terminals and the antidromic propagation of action potentials along the axons excited $[75,76]$. Signs of regional tactile allodynia confined to the cutaneous innervation areas of the trigeminal and upper cervical nerves are also observed, probably due to a capsaicin-induced central sensitization elicited by the transmitters released from the activated capsaicin-sensitive nerve endings [75,77]. These changes are later followed by the rapid (within minutes) development of selective regional chemo- and thermal analgesia, which is attributed to the impaired central transmission of the noxious impulses. The structural correlate of the analgesia produced by intracisternal and intrathecal injections of capsaicin is degeneration of the central terminals of the capsaicin-sensitive primary sensory neurones, as demonstrated by light- and electron microscopy [72,74-76]. Similarly to the effects of the high-dose systemic administration of capsaicin, intense argyrophilic degeneration is observed in the brainstem trigeminal caudal nucleus, the nucleus of the solitari tract and the superficial layers of the dorsal horn of the upper segments of the cervical spinal cord a few hours after the application of capsaicin $[75,76]$. At the electron microscopic level, selective degeneration of the glomerular C-type terminals is seen in these brainstem areas [76]. The degeneration of the central terminals may explain the observations on the depletion of substance $\mathrm{P}$, SOM, calcitonin gene-related peptide (CGRP), TRPV1 immunoreactivity and FRAP or thiamine monophosphatase (TMP) activity after intracisternal or intrathecal capsaicin and resiniferatoxin applications $[72,73,75,76,78,79]$. On spinal application at the level of the lumbar segments, apparent losses of nociceptor-specific neuronal markers occur from the superficial laminae of the spinal cord in the lumbar spinal segments, but not in the cervical and upper thoracic segments [72].

The trigeminal ganglion reveals neither morphological signs of neuronal degeneration nor depletion of the nociceptor-specific chemical markers observed after intracisternal application [76]. Furthermore, chemosensitive ganglion cells deprived of their central axons and connections to the central nervous system maintain their neurochemical phenotype and local regulatory functions [75-77]. In animals treated intracisternally with capsaicin, activation of the peripheral chemosensitive nerve endings in the chemodenervated skin region produced an apparently intact neurogenic inflammatory response. These experiments clearly showed a dissociation between the sensory afferent and local regulatory "efferent" functions of the capsaicin-sensitive primary afferent neurones and provided evidence that the local regulatory functions of these neurones are independent of their central connections [76]. This unique situation may also be of sig- 
nificance as regards vanilloid-based therapeutic interventions, since concerns relating to possible impairments of the sensory efferent/trophic functions of chemosensitive nerves following selective chemical ablation of the capsaicinsensitive primary sensory neurones could be prevented [7981].

\section{Perineural Capsaicin Treatment}

The perineural application of capsaicin is a special form of topical capsaicin treatment, since the peripheral nerves supplying a well-defined part of the skin or deep tissues are targeted in this situation. Capsaicin was originally applied in a gelfoam cuff, from which the drug reaches the nerve fibres within the nerve trunk by diffusion across the epineurinum $[21,82,83]$. There have also been reports on close neural injections [84-86], subperineural or even intraneural injections of capsaicin with similar effectiveness. As confirmed by many authors, the perineural application of capsaicin at 32 $\mathrm{mM}(1 \%)$ produces a highly selective and-long lasting (practically irreversible) functional blockade of the C-fiber afferents running in the affected nerve [87-91]. The acute morphological changes seen shortly after treatment are less characteristic: swollen C-fibres and the subsequent accumulation of cell organelles $[21,92]$. However, a fundamental change is observed in the relation between the C-fibres and the glial (Schwann) cells 2-3 weeks after the treatment: C-fibres, normally embedded in the cytoplasm of the Schwann cell processes, lose their tight contact with the glial cells and become unwrapped and closely packed together with other bare C-fibre axons [93]. Perineural capsaicin treatment does not produce an immediate degeneration of peripheral chemosensitive axons. Quantitative data have revealed a significant, but delayed reduction in the C-fibre count 2-3 months after treatment indicating a permanent loss of at least a subpopulation of C-fibre afferent neurones $[21,82,89]$. This peculiar slow, "dying back" type neuronal degeneration may result from a selective blockade of intraneuronal transport processes in chemosensitive primary afferent neurons, as will be discussed later [94]. Perineural capsaicin treatment exerts profound and selective effects on the neurochemical phenotype of chemosensitive primary sensory neurones. A few days after the treatment, severe downregulation and the depletion of several neurochemical markers are observed as regards both nociceptive dorsal root ganglion neurones and the somatotopically corresponding regions of the spinal dorsal horn. The levels of sensory neuropeptides, e.g. SP and CGRP and FRAP/TMP activity and IB4 binding are reduced after perineural treatment with capsaicin $[21,51,95]$. At the same time, a few markers display an increased expression: the transcription factor ATF3, a general marker of neuronal distress exhibits a highly selective upregulation in the small TRPV1-positive neurones, but not in the large TRPV1negative neurones a few days after capsaicin treatment (unpublished observation). This confirms the selectivity of capsaicin-induced axonal/neuronal degeneration. The membrane ganglioside GM1, the specific binding site for the "b" subunit of the cholera holotoxin, is overexpressed in the Cfibre nociceptive afferents, as demonstrated by the increased transganglionic transport of the CTb-HRP conjugate in the DRG ganglia and the superficial layers of the spinal dorsal horn following perineural capsaicin or RTX treatment $[96,97]$. Earlier observations indicated a rapid decrease in the sensitivity of DRG neurones and central terminals towards the neurotoxic effects of systemic capsaicin treatment [83]. This reduction in capsaicin sensitivity, which is also observed following transection of the peripheral nerves [98,99], is explained in part by the reduction of the capsaicin receptor protein. After cloning of the TRPV1 receptor, this presumption was confirmed by the strong decreases in both the mRNA and TRPV1 protein expression of small and medium sized dorsal root ganglion neurones and the TRPV1 immunoreactivity in the superficial layers of the spinal dorsal horn as early as 4 days after perineural capsaicin treatment [51]. Furthermore, use of a mustard oil-induced vascular labelling technique to identifiy the cutaneous regions innervated by the saphenous and the sciatic nerves, revealed almost complete elimination of the intra-epidermal nerve fibres in the skin regions innervated by the treated sciatic or saphenous nerves [59]. It is noteworthy that the morphology and density of the palisade-shaped hair follicle afferents, the terminals of low-threshold $A B$ cutaneous afferents, were unaffected.

Three phases of functional changes can be distinguished following the perineural application of capsaicin $[21,100]$ : during the first phase, capsaicin elicits the activation of $\mathrm{C}$ and $A \delta$ nerve fibres, producing cardiovascular reflexes, antidromic neurogenic vasodilatation and extravasation. During the second phase, there is a blockade of the $\mathrm{C}$ - and to a lesser extent A-fibre impulse conduction. The last phase is characterized by a total impairment of C-fibre functions distal to the site of capsaicin application. It includes complete chemical and thermal analgesia, and abolition of plasma protein or colloid extravasation $[59,82]$ and neurogenic vasodilatation $[101,102]$, i.e. neurogenic inflammation.

The development of inflammation-induced thermal hyperalgesia, which is critically dependent on the activity of the TRPV1 channel, is also prevented by prior perineural treatment with capsaicin [84]. The development of mechanical allodynia, which is transmitted by myelinated, capsaicininsensitive afferents, is also inhibited [84], probably due to the lack of nociceptive barrage preventing the central sensitization, a key mechanism of the tactile allodynia in the spinal dorsal horn.

In other types of hyperalgesia models (post-incision and post-operative) evoked by a standard incision in the skin of the plantar surface, both perineural capsaicin $[103,104]$ and resiniferatoxin [85] appeared to be highly effective in the prevention of thermal and mechanical hyperalgesia. Similarly, cold hyperalgesia too could be inhibited by perineural capsaicin treatment [105].

Perineural capsaicin application further produces a selective blockade across the application site of the retrograde and anterograde axonal transport processes in chemosensitive afferent nerve fibres. Inhibition of the intraneural transport of a variety of peptides and proteins such as nerve growth factor (NGF), horseradish peroxidase, SP, CGRP, SOM and FRAP has been demonstrated [94]. However, axons proximal to the application site preserve their capacity to transport exogenous and possibly endogenous proteins such as wheat germ agglutinin-peroxidase conjugate (WGA-HRP) or CTBHRP [106,107]. 
The integrity and the function of unmyelinated sympathetic C-fibre efferents and the myelinated low threshold $A ß-$ afferent and motor fibres remain intact; there are no disturbances in the mechano-sensitivity of the skin and deep tissues, or the sympathetic vasoregulation and sweat secretion after perineural capsaicin. Trophic disturbances in the chemodenervated skin areas have never been observed in animals after perineural treatment with capsaicin $[59,94]$.

An intriguing feature of perineural capsaicin treatment is its irreversible effect. The available data do not indicate any functional or morphological signs of re-innervation by chemosensitive nerve fibres following capsaicin-induced denervation. This is somewhat surprising, since the nerve trunk, the Schwann cells and the capsaicin-insensitive afferent and efferent nerve fibres remain intact after this treatment. Interestingly, collateral sprouting of intact chemosensitive nerves innervating skin areas adjacent to the chemodenervated skin and the consequent collateral reinnervation of the denervated skin has not been observed either after perineural application of capsaicin. This may be accounted for by the inhibition of collateral sprouting by the remaining intact nervous elements in the denervated skin or by the possible collateral damage of chemosensitive sensory ganglion neurones which innervate the adjacent intact skin areas [108].

\section{Neurotoxicity and Analgesia}

As outlined in the previous section of this review, capsaicin and related vanilloids can exert robust, but highly selective neurodegenerative (neurotoxic) effects in a welldefined population of somatic and visceral primary sensory neurones. Depending on the conditions of drug administration, vanilloids produce a severe overall disturbance in the metabolism of these cells, leading to the death and elimination of the affected neurones, or they exert a limited impairment/destruction of specific (central or peripheral) domains of the pseudounipolar neurons (Fig. 1). In this latter case, loss of the central or the peripheral connections of the chemosensitive sensory neurones with the spinal dorsal horn or the peripheral receptive field, respectively, interrupts the transmission of nociceptive signals, causing selective chemoand thermal analgesia. Moreover, after perineural (and in some cases topical) capsaicin application, but not after intrathecal capsaicin administration, the sensory efferent, local regulatory functions of the chemosensitive neurones are also abolished. Perineural application of capsaicin not only causes a complete absence of the neurogenic inflammatory reaction, but also reduces the intensity of inflammatory reactions that basically have a non-neurogenic, e.g. immunological origin $[31,32,109]$.

As far as we are aware, the neuronal effects in general, and the neurotoxic effects of vanilloids in particular, are mediated exclusively by the TRPV1 ion channel. Although there is evidence for the expression of TRPV1 in nonneuronal cells, such as epidermal and urothelial cells, Tlymphocytes, etc. $[110,111]$ and in neurones in the central nervous system, this channel is most abundant in a specific population of primary sensory neurones. TRPV1 is a member of the transient receptor potential family of ion channels characterized by a non-selective permeability for cations, including $\mathrm{Ca}^{2+}[14,15]$. There are many chemical and physical factors which activate the TRPV1 channel, including noxious heat, protons and exogenous or endogenous vanilloid compounds $[14,15,18]$. There is also a complex interaction between the thermal activation threshold and the transmembrane potential $[112,113]$. Numerous intracellular signalling pathways and mechanisms have been recognized which influence the gating mechanism by inducing an increase or decrease in the activation threshold (sensitization) or render the receptor unresponsive (desensitization) [18,45,114-116]. Such action is brought about by covalent posttranslational modifications of the channel protein (phosphorylation) or non-covalent interactions with regulatory factors (e.g. PIP2). Trafficking and translocation of the protein between the cell membrane and intracellular compartments have also been demonstrated as an additional level of the regulation of TRPV1 functions [115,117]. Apart from these mechanisms, which produce a rapid, short-term adjustment of the channel sensitivity, the long-term regulation of the TRPV1 gene expression, and finally the capsaicin sensitivity of the sensory neurones are strongly influenced by neurotrophic factors derived from peripheral target organs and transported to the parent cell body via retrograde axoplasmic transport. NGF was initially regarded as an effective regulator of neuronal capsaicin sensitivity and TRPV1 expression [118-120]. However, later studies revealed that other neurotrophins, such as glial-cell derived nerve growth factor (GDNF), also effectively increase the expression of TRPV1 [121-123]. It should be noted that nociceptors, including the capsaicin-sensitive primary sensory neurones are a non-uniform mixed population which possess different neurochemical and functional traits, including the sensitivity and dependence on neurotrophic factors $[124,125]$. This heterogeneity of the capsaicin-sensitive primary sensory neurones (of adult animals) could undoubtedly significantly influence the susceptibility of these cells towards capsaicin-induced neurotoxicity. Unfortunately, this issue has not yet been investigated in detail. It has been shown that there are primary sensory neurones which express the TRPV1 $\mathrm{mRNA} /$ protein at a significantly higher degree than other TRPV1-positive neurones [51,126]. On use of some neurochemical markers, this population appears to be unique, indicating a specific non-peptidergic (NGF receptor TrkA-negative), and IB4-negative population in which some neurons express the GDNF receptor subunit RET. Although it is plausible to suggest a mechanistic correlation between the level of expression of TRPV1 and the susceptibility of neurones towards capsaicin toxicity [51], it should be noted that this specific group comprises only a small proportion of the total neuronal population.

Early in vivo observations by Jancsó and co-workers revealed an increased accumulation of radioactive calcium in the sensory ganglia of capsaicin-treated (newborn) animals shortly (20 minutes) after the systemic administration of capsaicin. Ultrastructural histochemical analysis demonstrated $\mathrm{Ca}^{2+}$-containing deposits in the swollen mitochondria of small B-type sensory ganglion neurons, but not in the mitochondria of large A-type cells [29,30]. It has been concluded that this capsaicin-induced $\mathrm{Ca}^{2+}$ overload of the capsaicinsensitive neurones can contribute significantly to the neurotoxic action of this drug. The capsaicin-induced $\mathrm{Ca}^{2+}$ influx into the primary sensory neurones was later confirmed by many other groups, using histochemical, cellular electro- 
physiological and ratiometric imaging techniques [127-129]. It should be mentioned that capsaicin induced $\mathrm{Ca}^{2+}$ entry was also used as a functional trait during functional cloning experiments, which finally led to the cloning of the capsaicin receptor protein VR1 [14].

Numerous reports published recently were aimed at clarification of the mechanisms of capsaicin and vanilloidinduced cytotoxicity in different cell types, including cultured primary sensory neurones, heterologous expression systems, immortalized cell lines or neoplastic cells, many of them of non-neuronal origin [130,131]. In these studies different methods were employed to detect neurotoxicity and cell degeneration with different morphological or biochemical end-points. A distinction should be made between TRPV1-dependent, i.e. selective, and TRPV1-independent, direct, non-selective toxic effects of capsaicin and related vanilloids. The conclusions drawn from the observations concerning the mechanism of capsaicin-induced neuro(cyto)toxicity should be evaluated with some caution, with regard to these differences.

Early morphological observations indicated that high doses of capsaicin administered to rats produce significant changes in the integrity of the mitochondria in the affected sensory ganglion neurones. Although there are certain discrepancies among the (early) publications in connection with the time course, the severity and, most importantly the final outcome of these changes $[8,30,46,47,132,133]$, alterations in the mitochondrial functions seem to be critical in the mediation of the long-term effects of high concentration vanilloid/capsaicin administrations. It is not clear, however, to what extent the accumulation of $\mathrm{Ca}^{2+}$ in the mitochondrial matrix is the cause or a consequence of the impairment of the mitochondrial functions, including ATP synthesis and ion transport across the mitochondrial membrane [130]. There have been reports on the presence of functional TRPV1 channels not only in the plasma membrane, but also in the intracellular membranes of the endoplasmatic reticulum, which are of importance in the intracellular $\mathrm{Ca}^{2+}$ handling. It has also been proposed that TRPV1 receptors localized in the plasma membrane serve as store-operated $\mathrm{Ca}^{2+}$-channels, while TRPV1 channels in the endoplasmatic reticulum act as $\mathrm{Ca}^{2+}$-release receptors. Furthermore, it has been demonstrated that RTX, but not capsaicin can act directly on the IP3-dependent $\mathrm{Ca}^{2+}$-stores of the cells producing an intracellular $\mathrm{Ca}^{2+}$-transient in the absence of extracellular $\mathrm{Ca}^{2+}$ [134]. However, there are apparently no reports on the localization of TRPV1 in the mitochondrial membrane. Many researchers have suggested that an overload of intracellular $\mathrm{Ca}^{2+}$ depolarizes the mitochondrial transmembrane potential, which eventually leads to the opening of membrane potential transient (MPT) pores $[135,136]$. This non-selective permeabilization of the inner mitochondrial membrane, caused by the opening of MPT pores, leads to the loss of matrix components, a mitochondrial dysfunction, and substantial swelling of the mitochondria, with consequent outer membrane rupture and the release of apoptosis-inducing factors, including cytochrome $\mathrm{c}$ from the mitochondria [137]. Indeed, an increase in the cytoplasmic cytochrome-c level, a prominent consequence of the membrane disruption and disintegration of the mitochondria, has been confirmed in different cell types following the application of TRPV1 agonists in toxic concentration $[131,138]$. There are however (at least) two alternative mechanisms which may finally lead to cell degeneration or death: this can occur via either a necrotic or an apoptotic type of cell destruction. Necrosis can be regarded as death that ensues when a living cell is deprived of both glycolytic and oxidative ATP sources. Since neurones rely mainly on their mitochondrial oxidative ATP synthesis as the source of metabolic energy, it is plausible to conclude that acute destruction of the mitochondria will result in rapid necrosis of the neurones. The first reports, based on the observed morphological signs of capsaicin-induced neurodegeneration and rapid elimination of the destroyed cells in vivo, postulated the necrotic type of cell death, as a dominating process. Recent in vitro experiments using capsaicin or resiniferatoxin to activate TRPV1 receptors confirm rapid, necrotic-type destruction of the affected neurones [139]. There are also observations on capsaicin-induced apoptotic cell death in both neurones and non-neuronal cell lines $[130,140]$. Biochemical and molecular biological analysis revealed the activation of different components of the (programmed) cell death cascade, including different types of caspases and enzymes of the ubiquitin pathway [141]. Condensation of the chromatin, nuclear shrinkage and DNA fragmentation have also been observed following capsaicin application in sensory neurones and in other, TRPV1expressing cells. Association of the TRPV1 receptor (complex) with the Fas-associated Factor 1 (FAF1) protein was recently demonstrated (Kim, 2004). In certain cell types, FAF1 is linked to the Fas receptor, a membrane protein involved in the signal transduction of many pro-apoptotic effects [142]. Although FAF1 alone is not able to activate downstream elements of the intracellular signalling of the death cascade, its role in TRPV1 activation-induced apoptosis can not be excluded.

Impairment of the mitochondrial functions and uncoupling of the terminal oxidation also induces an increased production of reactive oxygen species (ROS), which play a crucial role in the neurotoxicity and neurodegeneration in a variety of neurodegenerative diseases. An increased production of ROS has been demonstrated after capsaicin application in TRPV1-transfected HEK cells; inhibition of ROS production, however, did not influence the development of apoptotic cell death [130]. It was therefore concluded that ROS do not play a significant role in capsaicin-induced apoptosis/cytotoxicity.

It is highly possible that high concentrations of capsaicin in vivo produce neuronal degeneration and death via a mixed mechanism, causing an acute, necrotic-type degeneration in specific population(s) of capsaicin-sensitive neurones, but a delayed-type (apoptotic) cell death in other population(s) of sensory neurones. This assumption is supported by the finding that, under in vitro conditions capsaicin produced both necrosis and apoptosis; the ratio of these events depended on the capsaicin concentration and on the TRPV1 expression of the transfected cells [130].

These considerations hold for the neurodegenerative effects of capsaicin and related vanilloids after systemic administration of these drugs to adult and newborn animals in high, toxic doses. In the case of perineural, intrathecal or topical application of vanilloids, there are no signs of an 
acute degeneration of sensory neurones in the related sensory ganglia. In these cases, in contrast with the systemic capsaicin application, the local concentration of capsaicin in the proximity of the nerve cell soma is presumably too low to induce any detectable morphological alterations in the primary sensory neurones. Following perineural capsaicin, a delayed type of neuronal degeneration, i.e. the loss of sensory neurones and transganglionic degeneration or loss of the central nerve terminals, has been proposed. A significant reduction in the number of sensory neurones in the affected dorsal root ganglion neurones has been demonstrated following transection or other non-selective mechanical injury of peripheral nerves [143-145]. Ultrastructural studies have disclosed a significant reduction in the number of glomerular-type afferent terminals in the superficial layers of the spinal dorsal horn, pointing to a possible transganglionic degeneration of primary sensory neurones $[146,147]$. Since the tendency to neuronal loss was reversible on the application of high doses of NGF onto the proximal stump of the transected nerve, a critical role of the withdrawal of NGF (and probably other trophic factors) transported retrogradely to the perikarya under normal conditions was proposed in the mechanism of the axotomy-induced transganglionic degeneration [93]. It is plausible to assume that, after perineural (intracutaneous) capsaicin treatment, which causes a selective destruction of the peripheral axons of C-fibre afferent neurones, a similar, but restricted transganglionic degeneration may occur in the spinal cord. Use of the capsaicin gap technique based on the systemic capsaicin treatment-induced argyrophilic degeneration of capsaicin-sensitive central terminals revealed an almost complete depletion of these terminals in the topographically related regions of the spinal dorsal horn corresponding to the treated peripheral nerves [83]. However later observations showed a concomitant decrease in the sensitivity to capsaicin-induced nerve terminal degeneration following transection of the peripheral nerve $[98,99]$, and an axotomy- or perineural capsaicin treatment-induced downregulation of the TRPV1 receptor in both the spinal dorsal horn and the sensory ganglia [51]. The interpretation of the capsaicin gap therefore needs some refinement: during the given time frame ( 2 weeks p.o.), the loss of the capsaicin-induced argyrophilic degeneration may result mainly from the rapid loss of the capsaicin sensitivity rather than from a loss of central terminations. The transganglionic transport of a WGA-HRP conjugate, a specific marker of Cfibre afferents, and CTb-HRP, a marker whose transport is enhanced in injured C-fibre afferents, was recently demonstrated 2 weeks after axotomy or perineural capsaicin treatment, indicating the presence and survival of a substantial population of $\mathrm{C}$-fibre terminals, in the spinal dorsal horn at this time $[106,107,148]$.

Overall, there is substantial evidence that capsaicin and related vanilloids cause obvious and selective neurodegeneration and neuronal death in a subset of primary sensory neurones in both neonate and adult animals. After systemic administration, all domains of the primary sensory neurones are affected, but the necrotic and probably to a lesser extent also the apoptotic neuron death is mainly due to a direct action of capsaicin on the TRPV1 channels located in the plasma membrane and intracellular membrane structures. Both the capsaicin-induced $\mathrm{Ca}^{2+}$ overload and the impaired mitochondrial functions are of major importance in these processes. Delayed-type neurodegeneration, caused by a cessation of the supply of NGF and other neurotrophins due to the blockade of the axonal transport and/or the destruction of the peripheral axons, might complete the ongoing degeneration process. In sharp contrast, different types of localized capsaicin/vanilloid applications, including perineural capsaicin treatment, do not induce acute degeneration/death of the nociceptive sensory ganglion neurones, and the loss of Ctype sensory fibres, which becomes evident only weeks after the treatment might result in part from delayed degeneration and death of a limited number of sensory neurones.

\section{The Perspectives of TRPV1 Agonists in the Management of Pain}

Observations concerning the analgesic effects of capsaicin and other vanilloid agents in animal experiments indicated that drugs with TRPV1 agonist potency may be considered for the management of pain in man. The possible use of capsaicin for the management of pain of peripheral origin was suggested some 30 years ago on the basis of animal studies showing marked increases in thermal and chemical nociceptive thresholds and a complete abolition of neurogenic inflammation following the local application of capsaicin onto peripheral nerves [149]. Further studies have confirmed and extended these observations and demonstrated that perineural capsaicin treatment also effectively and selectively inhibits the function of chemosensitive (capsaicin-sensitive) nociceptor afferents in species other than the rat and mouse, including the rabbit, cat and monkey, resulting in a defunctionalization of nociceptive somatic and visceral sensory afferent neurones $[21,90,100]$. Despite these encouraging findings in animal species, vanilloid compounds have been used only externally or topically to inhibit the function of chemosensitive afferent nerves in man $[18,116,150]$. However, such local treatment is impracticable for the management of severe chronic neuropathic or cancer pain. The findings in animal species as discussed in this review strongly suggest that perineural and intrathecal applications of vanilloid agonists may prove useful approaches for pain relief under such conditions [151]. Capsaicin treatment of peripheral nerves which serve tissues from which pain may originate due to localized pathologies associated with pain may confer suitable antinociception by disrupting the conduction of noxious stimuli to the central nervous system. Studies showing an increase in nociceptive thresholds in human subjects after high-dose epidermal application or the intradermal injection of capsaicin support this assumption, for such treatments are very likely to reach the preterminal segments of the peripheral axons, producing effects resembling the actions of perineural treatment with capsaicin $[56,150]$. Concerns as to possible unwanted or maladaptive changes induced by perineural vanilloid treatment may include the possible pain-producing effects of TRPV1 agonists, traumatic/mechanical injury of the nerve and the consequences of selective, but partial C-fibre deafferentation. The excitation of C-fibre axons [91,100,152] upon direct application of capsaicin onto a nerve is moderate, transient and short-lasting and may be well managed by the concomitant use of local anaesthetics $[86,153]$. Deafferentation of the spinal cord brought about by the injuries to major nerve plexuses supplying the extremities may cause severe chronic 
pain which is difficult to manage by pharmacological or neurosurgical means. Hence, the possibility of the development of central pain by any procedure causing even partial deafferentation of the spinal dorsal horn should be considered [154]. The available experimental evidence indicates that perineural treatment results in an at least a partial loss of peripheral unmyelinated axons and possibly DRG cell loss and consequent deafferentation of the substantia gelatinosa of the spinal dorsal horn $[21,82,89]$. However, this deafferentation is strictly confined to C-fibre afferents and there are no reports in the literature indicative of signs of deafferentation pain. Trophic functions are also known to be impaired by peripheral nerve injuries. Although perineural treatment results in the complete abolition of neurogenic sensory vasodilatation and plasma extravasation, i.e. neurogenic inflammation, which bears an important protective role under (patho)physiological conditions in the skin, cutaneous changes characteristic of trophic disturbances, e.g. skin erosions, were not observed in rodents after perineural treatment with capsaicin $[59,94]$.

Intrathecal and intracisternal injections of capsaicin caused the selective degeneration of C-fibre capsaicin-sensitive primary afferent terminals in the upper spinal dorsal horn, as demonstrated in light and electron microscopic studies [72,74-76]. There is some evidence that dorsal root fibres are not affected directly by this treatment, and the peripheral "efferent" local regulatory functions of chemosensitive nerve endings remain intact following the administration of capsaicin into the subarachnoid space [76]. Although injection of capsaicin into the subarachnoid space induces a highly selective degeneration of primary afferent nerve terminals, this is apparently not associated with persistent pain or hyperalgesia $[72,75,76]$, indicating that deafferentation pain does not develop. It appears, therefore, that the consequences of selective C-fibre deafferentation are substantially different from those of spinal deafferentation, which commences after lesions of both myelinated and unmyelinated dorsal root fibres.

A seminal trait of perineural and intrathecal/intracisternal capsaicin treatment is their largely irreversible nature $[21,82,83]$. The permanent loss of thermal and chemical pain sensations together with maintained sensitivity to noxious mechanical stimuli may not be critical for patients with severe pain of neuropathic or malignant origin. However, the pros and cons need to be considered carefully. Intrathecal injections of capsaicin may prove to be an efficient way to reduce pain of inflammatory or cancer origin in the thoracic, abdominal and pelvic regions. Further studies are required to clarify the effects of intrathecal injections of capsaicin, in particular with regard to the regulation of visceral functions, such as bladder emptying [78].

Although capsacin is the archetypical sensory neurotoxin used first to evoke defunctionalization/degeneration of chemosensitive primary sensory neurones some other vanilloids (and TRPV1 agonists) exhibit similar or even higher potency to produce selective neurotoxicity in nociceptors. For example resiniferatoxin is generally considered to have a $100-$ 1000 fold higher potency to activate and destroy capsaicinsensitive primary sensory neurones [155]. It has been claimed to have even more favourable pharmacokinetic and pharmacodynamic properties than those of capsaicin [156] The arguments in support of resiniferatoxin seem to be well substantiated by findings such as its reduced pungency following topical (intravesical) administration [64,157], but others seem to be more circumstantial, such as the claim for its better toxicological properties. Such claims are otherwise not of great significance, if we consider only the local (topi$\mathrm{cal}$, perineural or subarachnoid/epidural) therapeutic administration of vanilloids, which invovles a relatively small quantity of drug, applied for a limited time with low frequency. A major advantage of capsaicin is its widespread use (even as a food constituent), and the large body of evidence that has accumulated on its biological and pharmacological actions in animal and human studies. The information available on the actions of capsaicin under clinical conditions is expected to increase further in the near future since new formulas containing substantially higher concentrations of capsaicin than those of the earlier preparations have received permission for therapeutic use (topical or epicutaneous application) from the regulatory agencies in the USA and Europe [56,150,153, $158,159]$. The accessibility of high-concentration medicalgrade capsaicin preparations may also pave the way for the development and testing of more invasive (and targeted) therapeutic strategies, such as tissue infiltration, intraarticular and intrathecal injections and perineural applications.

Two new lines of development involving TRPV1 agonist-based therapeutic approaches could also be of some interest. Apart from the well-known "exogenous" TRPV1 agonists, endogenous TRPV1 agonists may also exert selective defunctionalization and degeneration of the capsaicinsensitive nerves $[151,160]$, possibly eliminating the concerns relating to the tolerability and toxicity of TRPV1 agonist drugs. Another concept might be the selective, but reversible blockade of the capsaicin-sensitive peripheral nerves by use of a combination of TRPV1 agonist (capsaicin) and watersoluble local anaesthetic drug able to ingress through activated, but not inactive TRPV1 channels [161]. It has been demonstrated that the drug QX-314 can effectively and reversibly inhibit conduction in the C-fibres previously activated by low concentrations of capsaicin $[161,162]$. It is worthy of mention that capsaicin at the doses/concentrations used in these experiments may exert some analgesic actions by virtue of its selective neurotoxic/axonotoxic actions on Cfibre nociceptors $[55,71,92]$.

\section{CONCLUDING REMARKS}

The inclusion of exogenous vanilloid agents of plant or synthetic origin or endogenous vanilloid compounds (endovanilloids) with TRPV1 receptor agonist properties into the therapeutic arsenal of pain management offers a promising novel approach for the treatment of chronic pain of neuropathic or malignant origin. Through careful choice of the appropriate route and dose for the administration of vanilloid agonists, selective targeting of the primary afferent fibres which convey nociceptive information from the diseased organs and tissues to the central nervous system seems possible. The large body of available experimental evidence indicates that vanilloid agonists exert their antinociceptive action through TRPV1 receptor-mediated selective neurotoxic/neurodegenerative effects directed against somatic and 
visceral C-fibre nociceptive primary afferent fibres. A1though the effects of capsaicin applied onto peripheral nerves or injected into the subarachnoid space appear to be permanent and irreversible, further studies are needed to clarify the long-term effects and possible central and peripheral neuroplastic changes elicited by such treatment. Finally, it is expected that vanilloid agonists will broaden the palette of analgesic drugs which do not cause addiction and tachyphylaxis.

\section{ACKNOWLEDGMENTS}

This study was supported by OTKA K63663, OTKA PD73259, ETT 193/2006; RET-08/2004. Péter Sántha was supported by the János Bolyai Scholarship of the Hungarian Academy of Sciences.

\section{REFERENCES}

[1] Jancsó, G. Histamine, capsaicin and neurogenic inflammation. A historical note on the contribution of Miklós (Nicholas) Jancsó (1903-1966) to sensory pharmacology. In: Advances in Psychoneuroimmunology, Berczi, I.; Szelényi, J., Ed.; Plenum Press: New York, 1994, pp. 17-23.

[2] Jancsó, N.; Jancsó-Gábor, A. Dauerausschaltung der chemischen Schmerzempfindlichkeit durch Capsaicin. Arch. Exp. Path. Pharmak., 1959, 236, 142-143.

[3] Jancsó, N. Role of the nerve terminals in the mechanism of inflammatory reactions. Bull. Millard Fillmore Hosp., 1960, 7, 5377.

[4] Jancsó, N. Desensitization with Capsaicin as a Tool for Studying the Function of Pain Receptors; Pergamon Press: Oxford, 1968; pp. 33-55.

[5] Maggi, C. A.; Meli, A. The sensory-efferent function of capsaicinsensitive sensory neurons. Gen. Pharmacol., 1988, 19(1), 1-43.

[6] Holzer, P. Neurogenic vasodilatation and plasma leakage in the skin. Gen. Pharmacol., 1998, 30(1), 5-11.

[7] Porszász, J.; Jancsó, N. Studies on the action potentials of sensory nerves in animals desensitized with capsaicine. Acta Physiol. Acad. Sci. Hung., 1959, 16, 299-306.

[8] Jancsó, G.; Király, E.; Jancsó-Gábor, A. Pharmacologically induced selective degeneration of chemosensitive primary sensory neurones. Nature, 1977, 270(5639), 741-743.

[9] Jancsó, G.; Király, E. Sensory neurotoxins: chemically induced selective destruction of primary sensory neurons. Brain Res., 1981, 210(1-2), 83-89

[10] Jancsó, G.; Király, E.; Such, G.; Joó, F.; Nagy, A. Neurotoxic effect of capsaicin in mammals. Acta Physiol. Hung., 1987, 69(34), 295-313.

[11] Holzer, P. Capsaicin: cellular targets, mechanisms of action, and selectivity for thin sensory neurons. Pharmacol. Rev., 1991, 43(2), 143-201.

[12] Lembeck, F.; Holzer, P. Substance P as neurogenic mediator of antidromic vasodilation and neurogenic plasma extravasation. Naunyn Schmiedebergs Arch. Pharmacol., 1979, 310(2), 175-183.

[13] Gamse, R.; Holzer, P.; Lembeck, F. Decrease of substance P in primary afferent neurones and impairment of neurogenic plasma extravasation by capsaicin. Br. J. Pharmacol., 1980, 68(2), 207213.

[14] Caterina, M. J.; Schumacher, M. A.; Tominaga, M.; Rosen, T. A.; Levine, J. D.; Julius, D. The capsaicin receptor: a heat-activated ion channel in the pain pathway. Nature, 1997, 389(6653), 816-824.

[15] Tominaga, M.; Caterina, M. J.; Malmberg, A. B.; Rosen, T. A.; Gilbert, H.; Skinner, K.; Raumann, B. E.; Basbaum, A. I.; Julius, D. The cloned capsaicin receptor integrates multiple painproducing stimuli. Neuron, 1998, 21(3), 531-543.

[16] Caterina, M. J.; Leffler, A.; Malmberg, A. B.; Martin, W. J.; Trafton, J.; Petersen-Zeitz, K. R.; Koltzenburg, M.; Basbaum, A. I.; Julius, D. Impaired nociception and pain sensation in mice lacking the capsaicin receptor. Science, 2000, 288(5464), 306-313.

[17] Davis, J. B.; Gray, J.; Gunthorpe, M. J.; Hatcher, J. P.; Davey, P. T.; Overend, P.; Harries, M. H.; Latcham, J.; Clapham, C.; Atkinson, K.; Hughes, S. A.; Rance, K.; Grau, E.; Harper, A. J.; Pugh, P. L.; Rogers, D. C.; Bingham, S.; Randall, A.; Sheardown, S. A. Va- nilloid receptor-1 is essential for inflammatory thermal hyperalgesia. Nature, 2000, 405(6783), 183-187.

[18] Nagy, I.; Sántha, P.; Jancsó, G.; Urbán, L. The role of the vanilloid (capsaicin) receptor (TRPV1) in physiology and pathology. Eur. J. Pharmacol., 2004, 500(1-3), 351-369.

[19] Nagy, J. I.; Hunt, S. P.; Iversen, L. L.; Emson, P. C. Biochemical and anatomical observations on the degeneration of peptidecontaining primary afferent neurons after neonatal capsaicin. $\mathrm{Neu}$ roscience, 1981, 6(10), 1923-1934.

[20] Hiura, A.; Ishizuka, H. Changes in features of degenerating primary sensory neurons with time after capsaicin treatment. Acta Neuropathol., 1989, 78(1), 35-46.

[21] Jancsó, G. Pathobiological reactions of C-fibre primary sensory neurones to peripheral nerve injury. Exp. Physiol., 1992, 77(3), 405-431

[22] Jancsó, G.; Király, E.; Such, G.; Joó, F.; Nagy, A. Neurotoxic effect of capsaicin in mammals. Acta Physiol. Hung., 1987, 69(34), 295-313.

[23] Jancsó, G.; Király, E. Distribution of chemosensitive primary sensory afferents in the central nervous system of the rat. J. Comp. Neurol., 1980, 190(4), 781-792.

[24] Jancsó, G.; Király, E.; Jancsó-Gábor, A. Chemosensitive pain fibres and inflammation. Int. J. Tissue React., 1980, 2 57-66.

[25] Hiura, A. Neuroanatomical effects of capsaicin on the primary afferent neurons. Arch. Histol. Cytol., 2000, 63(3), 199-215.

[26] Hiura, A.; Lopez, V. E.; Ishizuka, H. Age-dependent attenuation of the decrease of $\mathrm{C}$ fibers by capsaicin and its effects on responses to nociceptive stimuli. Somatosens. Mot. Res., 1992, 9(1), 37-43.

[27] Valtschanoff, J. G.; Rustioni, A.; Guo, A.; Hwang, S. J. Vanilloid receptor VR1 is both presynaptic and postsynaptic in the superficial laminae of the rat dorsal horn. J. Comp. Neurol., 2001, 436(2), 225 235.

[28] Jancsó, G. Selective degeneration of chemosensitive primary sensory neurons induced by capsaicin - glial changes. Cell Tissue Res., 1978, 195(1), 145-152.

[29] Jancsó, G.; Sávay, G.; Király, E. Appearance of histochemically detectable ionic calcium in degenerating primary sensory neurons. Acta Histochem., 1978, 62(2), 165-169.

[30] Jancsó, G.; Karcsú, S.; Király, E.; Szebeni, A.; Tóth, L.; Bácsy, E.; Joó, F.; Párducz, A. Neurotoxin induced nerve cell degeneration: possible involvement of calcium. Brain Res., 1984, 295(2), 211216.

[31] Jancsó, G. Neurogenic Inflammation in Health and Disease; 1st ed.; Elsevier: Amsterdam, 2009.

[32] Jancsó, G.; Katona, M.; Horváth, V.; Sántha, P.; Nagy J. Sensory nerves as modulators of cutaneous inflammatory reactions in health and disease, in Neurogenic Inflammation in Health and Disease, 1st ed.; Jancsó, G., Ed.; Elsevier: Amsterdam, 2009; Chapter 1, pp. 3-36.

[33] Jancsó, G.; Obál, F., Jr.; Tóth-Kása, I.; Katona, M.; Husz, S. The modulation of cutaneous inflammatory reactions by peptidecontaining sensory nerves. Int. J. Tissue React., 1985, 7(6), 449457.

[34] Sann, H.; Dux, M.; Schemann, M.; Jancsó, G. Neurogenic inflammation in the gastrointestinal tract of the rat. Neurosci. Lett., 1996 219(3), 147-150.

[35] Maggi, C. A.; Borsini, F.; Santicioli, P.; Geppetti, P.; Abelli, L. Evangelista, S.; Manzini, S.; Theodorsson-Norheim, E.; Somma V.; Amenta, F.; . Cutaneous lesions in capsaicin-pretreated rats. A trophic role of capsaicin-sensitive afferents? Naunyn Schmiedebergs Arch. Pharmacol., 1987, 336(5), 538-545.

[36] Thomas, D. A.; Dubner, R.; Ruda, M. A. Neonatal capsaicin treatment in rats results in scratching behavior with skin damage: potential model of non-painful dysesthesia. Neurosci. Lett., 1994, 171(12), 101-104.

[37] Jancsó, G.; JancsóGábor, A. Effect of Capsaicin on Morphine Analgesia - Possible Involvement of Hypothalamic Structures. Naunyn-Schmiedebergs Arch. Pharmacol., 1980, 311(3), 285-288.

[38] Jancsó, G. Sensory nerves as modulators of inflammatory reactions, in Antidromic Vasodilatation and Neurogenic Inflammation, Chahl, J.; Szolcsányi, J.; Lembeck, F., Ed.; Akadémiai Kiadó: Budapest, 1984; pp. 207-222.

[39] Hayes, A. G.; Oxford, A.; Reynolds, M.; Shingler, A. H.; Skingle, M.; Smith, C.; Tyers, M. B. The effects of a series of capsaicin analogues on nociception and body temperature in the rat. Life Sci. 1984, 34(13), 1241-1248. 
[40] Buck, S. H.; Burks, T. F. The neuropharmacology of capsaicin: review of some recent observations. Pharmacol. Rev., 1986, 38(3), 179-226.

[41] Maggi, C. A.; Meli, A. The sensory-efferent function of capsaicinsensitive sensory neurons. Gen. Pharmacol., 1988, 19(1), 1-43.

[42] Fitzgerald, M. Capsaicin and sensory neurones-a review. Pain, 1983, 15(2), 109-130.

[43] Dray, A. Mechanism of action of capsaicin-like molecules on sensory neurons. Life Sci., 1992, 51(23), 1759-1765.

[44] Hucho, T.; Levine, J. D. Signaling pathways in sensitization: toward a nociceptor cell biology. Neuron, 2007, 55(3), 365-376.

[45] Vergnolle, N. Postinflammatory visceral sensitivity and pain mechanisms. Neurogastroenterol. Motil., 2008, 20 (Suppl 1), 7380.

[46] Joó, F.; Szolcsányi, J.; Jancsó-Gábor, A. Mitochondrial alterations in the spinal ganglion cells of the rat accompanying the long-lasting sensory disturbance induced by capsaicin. Life Sci., 1969, 8(11), 621-626.

[47] Jancsó, G.; Király, E.; Joó, F.; Such, G.; Nagy, A. Selective degeneration by capsaicin of A subpopulation of primary sensory neurons in the adult-rat. Neurosci. Lett., 1985, 59(2), 209-214.

[48] Jancsó, G.; Knyihár, E. Functional linkage between nociception and fluoride-resistant acid phosphatase activity in the Rolando substance. Neurobiology, 1975, 5(1), 42-43.

[49] Gamse, R.; Leeman, S. E.; Holzer, P.; Lembeck, F. Differential effects of capsaicin on the content of somatostatin, substance P, and neurotensin in the nervous system of the rat. Naunyn Schmiedebergs Arch. Pharmacol., 1981, 317(2), 140-148.

[50] Jessell, T. M.; Iversen, L. L.; Cuello, A. C. Capsaicin-induced depletion of substance P from primary sensory neurones. Brain Res., 1978, 152(1), 183-188.

[51] Szigeti, C.; Körtvély, E.; Sántha, P.; Nyári, T.; Gulya, K.; Jancsó, G. Changes in TRPV1 receptor expression following perineural treatment with capsaicin and resiniferatoxin: implications for the analgesic effects of vanilloids. $5^{\text {th }}$ Forum of European Neuroscience, Vienna, Austria, 2006, A215.24.

[52] Sann, H.; Jancsó, G.; Ambrus, A.; Pierau, F. K. Capsaicin treatment induces selective sensory degeneration and increased sympathetic innervation in the rat ureter. Neuroscience, 1995, 67(4), 953966.

[53] Chung, K.; Schwen, R. J.; Coggeshall, R. E. Ureteral axon damage following subcutaneous administration of capsaicin in adult rats. Neurosci. Lett., 1985, 53(2), 221-226.

[54] Chung, K.; Klein, C. M.; Coggeshall, R. E. The receptive part of the primary afferent axon is most vulnerable to systemic capsaicin in adult rats. Brain Res., 1990, 511(2), 222-226.

[55] Dux, M.; Sántha, P.; Jancsó, G. Capsaicin-sensitive neurogenic sensory vasodilatation in the dura mater of the rat. J. Physiol., 2003, 552(3), 859-867.

[56] Nolano, M.; Simone, D. A.; Wendelschafer-Crabb, G.; Johnson, T.; Hazen, E.; Kennedy, W. R. Topical capsaicin in humans: parallel loss of epidermal nerve fibers and pain sensation. Pain, 1999, 81(12), 135-145.

[57] Reilly, D. M.; Ferdinando, D.; Johnston, C.; Shaw, C.; Buchanan, K. D.; Green, M. R. The epidermal nerve fibre network: characterization of nerve fibres in human skin by confocal microscopy and assessment of racial variations. Br. J. Dermatol., 1997, 137(2), 163-170.

[58] Simone, D. A.; Nolano, M.; Johnson, T.; Wendelschafer-Crabb, G.; Kennedy, W. R. Intradermal injection of capsaicin in humans produces degeneration and subsequent reinnervation of epidermal nerve fibers: Correlation with sensory function. J. Neurosci., 1998, 18(21), 8947-8954.

[59] Dux, M.; Sann, H.; Jancsó, G. Changes in fibre populations of the rat hairy skin after selective chemodenervation by capsaicin. Eur. J. Neurosci., 1998, 10299.

[60] Maggi, C. A.; Santicioli, P.; Meli, A. The effects of topical capsaicin on rat urinary-bladder motility in vivo. Eur. J. Pharmacol., 1984, 103(1-2), 41-50.

[61] Maggi, C. A.; Lippe, I. T.; Giuliani, S.; Abelli, L.; Somma, V.; Geppetti, P.; Jancsó, G.; Santicioli, P.; Meli, A. Topical versus systemic capsaicin desensitization - specific and unspecific effects as indicated by modification or reflex micturition in rats. Neuroscience, 1989, 31(3), 745-756.
[62] Fowler, C. J.; Jewkes, D.; McDonald, W. I.; Lynn, B.; de Groat, W. C. Intravesical capsaicin for neurogenic bladder dysfunction. Lancet, 1992, 339(8803), 1239.

[63] Szállási, A.; Fowler, C. J. After a decade of intravesical vanilloid therapy: still more questions than answers. Lancet Neurol., 2002, 1(3), 167-172.

[64] Cruz, F.; Guimaraes, M.; Silva, C.; Reis, M. Suppression of bladder hyperreflexia by intravesical resiniferatoxin. Lancet, 1997, 350(9078), 640-641.

[65] Cruz, F. Mechanisms involved in new therapies for overactive bladder. Urology, 2004, 63(3 Suppl 1), 65-73.

[66] Fowler, C. J. Intravesical treatment of overactive bladder. Urology, 2000, 55(5A Suppl), 60-64.

[67] Apostolidis, A.; Brady, C. M.; Yiangou, Y.; Davis, J.; Fowler, C. J.; Anand, P. Capsaicin receptor TRPV1 in urothelium of neurogenic human bladders and effect of intravesical resiniferatoxin. Urology, 2005, 65(2), 400-405.

[68] Dasgupta, P.; Chandiramani, V. A.; Beckett, A.; Scaravilli, F.; Fowler, C. J. The effect of intravesical capsaicin on the suburothelial innervation in patients with detrusor hyper-reflexia. BJU Int., 2000, 85(3), 238-245.

[69] Avelino, A.; Cruz, F. Peptide immunoreactivity and ultrastructure of rat urinary bladder nerve fibers after topical desensitization by capsaicin or resiniferatoxin. Auton. Neurosci., 2000, 86(1-2), 3746.

[70] Silva, C.; Avelino, A.; Souto-Moura, C.; Cruz, F. A light- and electron-microscopic histopathological study of human bladder mucosa after intravesical resiniferatoxin application. BJU Int., 2001, 88(4), 355-360.

[71] Király, E.; Jancsó, G.; Hajós, M. Possible Morphological Correlates of Capsaicin Desensitization. Brain Res., 1991, 540(1-2), 279282.

[72] Yaksh, T. L.; Farb, D. H.; Leeman, S. E.; Jessell, T. M. Intrathecal capsaicin depletes substance $\mathrm{P}$ in the rat spinal cord and produces prolonged thermal analgesia. Science, 1979, 206(4417), 481-483.

[73] Nagy, J. I.; Emson, P. C.; Iversen, L. L. A re-evaluation of the neurochemical and antinociceptive effects of intrathecal capsaicin in the rat. Brain Res., 1981, 211(2), 497-502.

[74] Palermo, N. N.; Brown, H. K.; Smith, D. L. Selective neurotoxic action of capsaicin on glomerular C-type terminals in rat substantia gelatinosa. Brain Res., 1981, 208(2), 506-510.

[75] Jancsó, G. Intracisternal capsaicin - selective degeneration of chemosensitive primary sensory afferents in the adult-rat. Neurosci. Lett., 1981, 27(1), 41-45.

[76] Gamse, R.; Jancsó, G.; Király, E. Intracisternal capsaicin: a novel approach for studying nociceptive sensory neurons, in Neurogenic Inflammation and Antidromic Vasodilatation, Chahl, J.; Szolcsányi, J.; Lembeck, F., Eds.; Akadémiai Kiadó: Budapest, 1984; pp. 93110.

[77] Jancsó, G.; Dux, M.; Sántha, P. Role of capsaicin-sensitive afferent nerves in initiation and maintenance of pathological pain. Behav. Brain Sci., 1997, 20(3), 454-455.

[78] Cruz, C. D.; Charrua, A.; Vieira, E.; Valente, J.; Avelino, A.; Cruz, F. Intrathecal delivery of resiniferatoxin (RTX) reduces detrusor overactivity and spinal expression of TRPV1 in spinal cord injured animals. Exp. Neurol., 2008, 214(2), 301-308.

[79] Jeffry, J. A.; Yu, S. Q.; Sikand, P.; Parihar, A.; Evans, M. S.; Premkumar, L. S. Selective targeting of TRPV1 expressing sensory nerve terminals in the spinal cord for long lasting analgesia. PLoS One, 2009, 4(9), e7021.

[80] Szabó, T.; Oláh, Z.; Iadarola, M. J.; Blumberg, P. M. Epidural resiniferatoxin induced prolonged regional analgesia to pain. Brain Res., 1999, 840(1-2), 92-98.

[81] Brown, D. C.; Iadarola, M. J.; Perkowski, S. Z.; Erin, H.; Shofer, F.; Lászlo, K. J.; Oláh, Z.; Mannes, A. J. Physiologic and antinociceptive effects of intrathecal resiniferatoxin in a canine bone cancer model. Anesthesiology, 2005, 103(5), 1052-1059.

[82] Jancsó, G.; Király, E.; Jancsó-Gábor, A. Direct evidence for an axonal site of action of capsaicin. Naunyn-Schmiedebergs Arch. Pharm., 1980, 313(1), 91-94.

[83] Jancsó, G.; Lawson, S. N. Transganglionic degeneration of capsaicin-sensitive C-fiber primary afferent terminals. Neuroscience, 1990, 39(2), 501-511.

[84] Kissin, I.; Bright, C. A.; Bradley, E. L., Jr. Selective and longlasting neural blockade with resiniferatoxin prevents inflammatory pain hypersensitivity. Anesth. Analg., 2002, 94(5), 1253-8. 
[85] Kissin, I.; Davison, N.; Bradley, E. L., Jr. Perineural resiniferatoxin prevents hyperalgesia in a rat model of postoperative pain. Anesth. Analg., 2005, 100(3), 774-80.

[86] Kissin, I. Vanilloid-induced conduction analgesia: selective, dosedependent, long-lasting, with a low level of potential neurotoxicity. Anesth. Analg., 2008, 107(1), 271-281.

[87] Sann, H.; Mccarthy, P. W.; Jancsó, G.; Pierau, F. K. Rt97 - A marker for capsaicin-insensitive sensory endings in the rat skin. Cell Tiss. Res., 1995, 282(1), 155-161.

[88] Baranowski, R.; Lynn, B.; Pini, A. The effects of locally applied capsaicin on conduction in cutaneous nerves in four mammalian species. Br. J. Pharmacol., 1986, 89(2), 267-276.

[89] Pini, A.; Baranowski, R.; Lynn, B. Long-term reduction in the number of $\mathrm{C}$-fibre nociceptors following capsaicin treatment of a cutaneous nerve in adult rats. Eur. J. Neurosci., 1990, 2(1), 89-97.

[90] Chung, J. M.; Lee, K. H.; Hori, Y.; Willis, W. D. Effects of capsaicin applied to a peripheral nerve on the responses of primate spinothalamic tract cells. Brain Res., 1985, 329(1-2), 27-38.

[91] Welk, E.; Petsche, U.; Fleischer, E.; Handwerker, H. O. Altered excitability of afferent $\mathrm{C}$-fibres of the rat distal to a nerve site exposed to capsaicin. Neurosci. Lett., 1983, 38(3), 245-250.

[92] Jancsó, G.; Ferrari, G.; Such, G.; Király, E.; Nagy, A.; Bujdosó, M. Morphological effects of capsaicin and and its analogues in newborn and adult animals. In: Tachykinin antagonists, Hakanson, R.; Sundler, F., Eds.; Elsevier: Amsterdam, New York, Oxford, 1985; pp. $35-44$.

[93] Jancsó, G. Pathobiological reactions of C-fiber primary sensory neurons to peripheral-nerve injury. Exp. Physiol., 1992, 77(3), 405431 .

[94] Gamse, R.; Petsche, U.; Lembeck, F.; Jancsó, G. Capsaicin applied to peripheral-nerve inhibits axoplasmic-transport of substance-P and somatostatin. Brain Res., 1982, 239(2), 447-462.

[95] Gibson, S. J.; McGregor, G.; Bloom, S. R.; Polak, J. M.; Wall, P. D. Local application of capsaicin to one sciatic nerve of the adult rat induces a marked depletion in the peptide content of the lumbar dorsal horn. Neuroscience, 1982, 7(12), 3153-3162.

[96] Mannion, R. J.; Doubell, T. P.; Gill, H.; Woolf, C. J. Deafferentation is insufficient to induce sprouting of A-fibre central terminals in the rat dorsal horn. J. Comp. Neurol., 1998, 393(2), 135-144.

[97] Jancsó, G.; Sántha, P.; Oszlács, O.; Nyári, T. Phenotypic switch of nociceptive primary sensory neurons induced by perineural treatment with capsaicin and resiniferatoxin. $5^{\text {th }}$ Forum of European Neuroscience, Vienna, Austria, 2006, A215.13.

[98] Jancsó, G.; Ambrus, A. Capsaicin sensitivity of primary sensory neurones and its regulation. In: Peripheral Neurons in Nociception: physio-Pharmacological Aspects, 1st ed; Besson, J. M.; Guilbaud, G.; Ollat, H., Eds.; John Libbey Eurotext: Paris, 1994; pp. 71-87.

[99] Jancsó, G.; Juhász, A.; Dux, M.; Sántha, P.; Domoki, F. Axotomy prevents capsaicin-induced sensory ganglion cell degeneration. Primary Sensory Neuron, 1997, 2(3), 159-165.

[100] Jancsó, G.; Such, G. Effects of capsaicin applied perineurally to the vagus nerve on cardiovascular and respiratory functions in the cat. J. Physiol., 1983, 341(8), 359-370.

[101] Domoki, F.; Sántha, P.; Bari, F.; Jancsó, G. Perineural capsaicin treatment attenuates reactive hyperaemia in the rat skin. Neurosci. Lett., 2003, 341(2), 127-130.

[102] Sántha, P.; Pierau, F.; Jancsó, G. Collateral sprouting of afferent vasodilatatory nerves into the denervated rat skin as assessed by laser Doppler imaging. Neuropeptides, 2002, 36, 473.

[103] Pospisilova, E.; Palecek, J. Post-operative pain behavior in rats is reduced after single high-concentration capsaicin application. Pain, 2006, 125(3), 233-243.

[104] Kang, S.; Wu, C.; Banik, R. K.; Brennan, T. J. Effect of capsaicin treatment on nociceptors in rat glabrous skin one day after plantar incision. Pain, 2010, $148(1), 128-140$.

[105] Hao, J. X.; Yu, W.; Xu, X. J.; Wiesenfeld-Hallin, Z. Capsaicinsensitive afferents mediate chronic cold, but not mechanical, allodynia-like behavior in spinally injured rats. Brain Res., 1996, 722(1-2), 177-180.

[106] Sántha, P.; Jancsó, G. Transganglionic transport of choleragenoid by capsaicin-sensitive $\mathrm{C}$-fibre afferents to the substantia gelatinosa of the spinal dorsal horn after peripheral nerve section. Neuroscience, 2003, 116(3), 621-627.

[107] Jancsó, G.; Sántha, P. Transganglionic transport of choleragenoid by injured $\mathrm{C}$ fibres to the substantia gelatinosa: relevance to neuropathic pain and hyperalgesia. In Hyperalgesia: Molecular Mecha- nisms and Clinical Implications, 1st ed.; Brune, K.; Handwerker, H. O., Eds.; IASP Press: Seattle, 2004; Vol. 30, Chapter IV/13, pp. $143-156$

[108] Jancsó, G.; Sántha, P.; Gecse, K. Peripheral nerve lesion-induced uptake and transport of choleragenoid by capsaicin-sensitive Cfibre spinal ganglion neurons. Acta Biol. Hung., 2002, 53(1-2), 7784.

[109] Donaldson, L. F.; McQueen, D. S.; Seckl, J. R. Neuropeptide gene expression and capsaicin-sensitive primary afferents: maintenance and spread of adjuvant arthritis in the rat. J. Physiol., 1995, 486(Pt 2), 473-482.

[110] Lee, H.; Caterina, M. J. TRPV channels as thermosensory receptors in epithelial cells. Pflugers Arch., 2005, 451(1), 160-167.

[111] Nagy, I.; Sántha, P.; Jancsó, G.; Urbán, L. The role of the vanilloid (capsaicin) receptor (TRPV1) in physiology and pathology. Eur. J. Pharmacol, 2004, 500(1-3), 351-369.

[112] Voets, T.; Droogmans, G.; Wissenbach, U.; Janssens, A.; Flockerzi, V.; Nilius, B. The principle of temperature-dependent gating in cold- and heat-sensitive TRP channels. Nature, 2004, 430(7001) 748-754.

[113] Nilius, B.; Mahieu, F.; Karashima, Y.; Voets, T. Regulation of TRP channels: a voltage-lipid connection. Biochem. Soc. Trans., 2007, 35(Pt 1), 105-108.

[114] Nicol, G. D.; Vasko, M. R. Unraveling the story of NGF-mediated sensitization of nociceptive sensory neurons: ON or OFF the Trks? Mol. Interv., 2007, 7(1), 26-41.

[115] Stein, C.; Clark, J. D.; Oh, U.; Vasko, M. R.; Wilcox, G. L.; Overland, A. C.; Vanderah, T. W.; Spencer, R. H. Peripheral mechanisms of pain and analgesia. Brain Res. Rev., 2009, 60(1), 90-113.

[116] Holzer, P. The pharmacological challenge to tame the transient receptor potential vanilloid-1 (TRPV1) nocisensor. Br. J. Pharmacol., 2008, 155(8), 1145-1162.

[117] Morenilla-Palao, C.; Planells-Cases, R.; Garcia-Sanz, N.; FerrerMontiel, A. Regulated exocytosis contributes to protein kinase C potentiation of vanilloid receptor activity. J. Biol. Chem., 2004, 279(24), 25665-25672.

[118] Winter, J.; Forbes, C. A.; Sternberg, J.; Lindsay, R. M. Nerve growth factor (NGF) regulates adult rat cultured dorsal root ganglion neuron responses to the excitotoxin capsaicin. Neuron, $\mathbf{1 9 8 8}$, 1(10), 973-981.

[119] Bevan, S.; Winter, J. Nerve growth factor (NGF) differentially regulates the chemosensitivity of adult rat cultured sensory neurons. J. Neurosci., 1995, $15(7 \mathrm{Pt} 1), 4918-4926$.

[120] Lindsay, R. M.; Lockett, C.; Sternberg, J.; Winter, J. Neuropeptide expression in cultures of adult sensory neurons: modulation of substance $\mathrm{P}$ and calcitonin gene-related peptide levels by nerve growth factor. Neuroscience, 1989, 33(1), 53-65.

[121] Ogun-Muyiwa, P.; Helliwell, R.; McIntyre, P.; Winter, J. Glial cell line derived neurotrophic factor (GDNF) regulates VR1 and substance P in cultured sensory neurons. Neuroreport, 1999, 10(10), 2107-2111.

[122] Priestley, J. V.; Michael, G. J.; Averill, S.; Liu, M.; Willmott, N. Regulation of nociceptive neurons by nerve growth factor and glial cell line derived neurotrophic factor. Can. J. Physiol. Pharmacol., 2002, 80(5), 495-505.

[123] Albers, K. M.; Woodbury, C. J.; Ritter, A. M.; Davis, B. M.; Koerber, H. R. Glial cell-line-derived neurotrophic factor expression in skin alters the mechanical sensitivity of cutaneous nociceptors. $J$. Neurosci., 2006, 26(11), 2981-2990.

[124] Silverman, J. D.; Kruger, L. Lectin and neuropeptide labeling of separate populations of dorsal root ganglion neurons and associated "nociceptor" thin axons in rat testis and cornea whole-mount preparations. Somatosens. Res., 1988, 5(3), 259-267.

[125] Snider, W. D.; McMahon, S. B. Tackling pain at the source: new ideas about nociceptors. Neuron, 1998, 20(4), 629-632.

[126] Michael, G. J.; Priestley, J. V. Differential expression of the mRNA for the vanilloid receptor subtype 1 in cells of the adult rat dorsal root and nodose ganglia and its downregulation by axotomy. $J$. Neurosci., 1999, 19(5), 1844-1854.

[127] Chard, P. S.; Bleakman, D.; Savidge, J. R.; Miller, R. J. Capsaicininduced neurotoxicity in cultured dorsal root ganglion neurons: in volvement of calcium-activated proteases. Neuroscience, 1995 65(4), 1099-1108

[128] Savidge, J. R.; Ranasinghe, S. P.; Rang, H. P. Comparison of intracellular calcium signals evoked by heat and capsaicin in cultured 
rat dorsal root ganglion neurons and in a cell line expressing the rat vanilloid receptor, VR1. Neuroscience, 2001, 102(1), 177-184.

[129] Dedov, V. N.; Roufogalis, B. D. Mitochondrial calcium accumulation following activation of vanilloid (VR1) receptors by capsaicin in dorsal root ganglion neurons. Neuroscience, 2000, 95(1), 183188 .

[130] Shin, C. Y.; Shin, J.; Kim, B. M.; Wang, M. H.; Jang, J. H.; Surh, Y. J.; Oh, U. Essential role of mitochondrial permeability transition in vanilloid receptor 1-dependent cell death of sensory neurons. Mol. Cell. Neurosci., 2003, 24(1), 57-68.

[131] Maccarrone, M.; Lorenzon, T.; Bari, M.; Melino, G.; Finazzi-Agro, A. Anandamide induces apoptosis in human cells via vanilloid receptors. Evidence for a protective role of cannabinoid receptors. $J$. Biol. Chem., 2000, 275(41), 31938-31945.

[132] Szolcsányi, J.; Jancsó-Gábor, A.; Joó, F. Functional and fine structural characteristics of the sensory neuron blocking effect of capsaicin. Naunyn Schmiedebergs Arch. Pharmacol., 1975, 287(2), 157-169.

[133] Ke, E.; Seress, L.; Szolcsányi, J. Neonatal capsaicin treatment results in prolonged mitochondrial damage and delayed cell death of B cells in the rat trigeminal ganglia. Neuroscience, 2002, 113(4), 925-937.

[134] Marshall, I. C.; Owen, D. E.; Cripps, T. V.; Davis, J. B.; McNulty, S.; Smart, D. Activation of vanilloid receptor 1 by resiniferatoxin mobilizes calcium from inositol 1,4,5-trisphosphate-sensitive stores. Br. J. Pharmacol., 2003, 138(1), 172-176.

[135] Bernardi, P.; Rasola, A. Calcium and cell death: the mitochondrial connection. Subcell. Biochem., 2007, 45, 481-506.

[136] Duchen, M. R. Mitochondria and calcium: from cell signalling to cell death. J. Physiol., 2000, 529(Pt 1), 57-68.

[137] Kluck, R. M.; Bossy-Wetzel, E.; Green, D. R.; Newmeyer, D. D. The release of cytochrome c from mitochondria: a primary site for Bcl-2 regulation of apoptosis. Science, 1997, 275(5303), 11321136.

[138] Davies, J. W.; Hainsworth, A. H.; Guerin, C. J.; Lambert, D. G. Pharmacology of capsaicin-, anandamide-, and N-arachidonoyldopamine-evoked cell death in a homogeneous transient receptor potential vanilloid subtype 1 receptor population. Br. J. Anaesth., 2010, 104(5), 596-602.

[139] Oláh, Z.; Szabó, T.; Kárai, L.; Hough, C.; Fields, R. D.; Caudle, R. M.; Blumberg, P. M.; Iadarola, M. J. Ligand-induced dynamic membrane changes and cell deletion conferred by vanilloid receptor 1. J. Biol. Chem., 2001, 276(14), 11021-11030.

[140] Jin, H. W.; Ichikawa, H.; Fujita, M.; Yamaai, T.; Mukae, K.; Nomura, K.; Sugimoto, T. Involvement of caspase cascade in capsaicin-induced apoptosis of dorsal root ganglion neurons. Brain Res., 2005, 1056(2), 139-144.

[141] Maity, R.; Sharma, J.; Jana, N. R. Capsaicin induces apoptosis through ubiquitin-proteasome system dysfunction. J. Cell. Biochem., 2010, 109(5), 933-942.

[142] Ghosh, A. K.; Basu, S. Fas-associated factor 1 is a negative regulator in capsaicin induced cancer cell apoptosis. Cancer Lett., 2010, 287(2), 142-149.

[143] Aldskogius, H.; Arvidsson, J.; Grant, G. The reaction of primary sensory neurons to peripheral nerve injury with particular emphasis on transganglionic changes. Brain Res., 1985, 357(1), 27-46.

[144] Aldskogius, H.; Risling, M. Effect of sciatic neurectomy on neuronal number and size distribution in the $\mathrm{L} 7$ ganglion of kittens. Exp. Neurol., 1981, 74(2), 597-604.

[145] Arvidsson, J.; Ygge, J.; Grant, G. Cell loss in lumbar dorsal root ganglia and transganglionic degeneration after sciatic nerve resection in the rat. Brain Res., 1986, 373(1-2), 15-21.
[146] Castro-Lopes, J. M.; Coimbra, A.; Grant, G.; Arvidsson, J. Ultrastructural changes of the central scalloped (C1) primary afferent endings of synaptic glomeruli in the substantia gelatinosa Rolandi of the rat after peripheral neurotomy. J. Neurocytol., 1990, 19(3), 329-337.

[147] Csillik, B.; Knyihár, E. Biodynamic plasticity in the Rolando substance. Prog. Neurobiol., 1978, 10(4), 203-230.

[148] Sugimoto, T.; Gobel, S. Primary neurons maintain their central axonal arbors in the spinal dorsal horn following peripheral nerve injury: an anatomical analysis using transganglionic transport of horseradish peroxidase. Brain Res., 1982, $248(2)$, 377-381.

[149] Jancsó, G.; Lynn, B. Possible use of capsaicin in pain therapy. Clin. J. Pain, 1987, 3, 123-126.

[150] Robbins, W. R.; Staats, P. S.; Levine, J.; Fields, H. L.; Allen, R. W.; Campbell, J. N.; Pappagallo, M. Treatment of intractable pain with topical large-dose capsaicin: preliminary report. Anesth. Analg., 1998, 86(3), 579-583.

[151] Jancsó, G.; Dux, M.; Oszlács, O.; Sántha, P. Activation of the transient receptor potential vanilloid-1 (TRPV1) channel opens the gate for pain relief. Br. J. Pharm., 2008, 155(8), 1139-1141.

[152] Such, G.; Jancsó, G. Axonal Effects of Capsaicin - An Electrophysiological Study. Acta Physiol. Hung., 1986, 67(1), 53-63.

[153] Simpson, D. M.; Gazda, S.; Brown, S.; Webster, L. R.; Lu, S. P.; Tobias, J. K.; Vanhove, G. F. Long-term safety of NGX-4010, a high-concentration capsaicin patch, in patients with peripheral neuropathic pain. J. Pain Symptom. Manage., 2010, 39(6), 1053-1064.

[154] Binder, A.; Baron, R. Postherpetic neuralgia--fighting pain with fire. Lancet Neurol., 2008, 7(12), 1077-1078.

[155] Szállási, A.; Blumberg, P. M. Resiniferatoxin, a phorbol-related diterpene, acts as an ultrapotent analog of capsaicin, the irritant constituent in red pepper. Neuroscience., 1989, 30(2), 515-520.

[156] Knotkova, H.; Pappagallo, M.; Szállási, A. Capsaicin (TRPV1 Agonist) therapy for pain relief: farewell or revival? Clin. J. Pain., 2008, 24(2), 142-154.

[157] Raisinghani, M.; Pabbidi, R. M.; Premkumar, L. S. Activation of transient receptor potential vanilloid 1 (TRPV1) by resiniferatoxin. J. Physiol., 2005, 567(Pt 3), 771-786.

[158] Malmberg, A. B.; Mizisin, A. P.; Calcutt, N. A.; von Stein, T.; Robbins, W. R.; Bley, K. R. Reduced heat sensitivity and epidermal nerve fiber immunostaining following single applications of a high-concentration capsaicin patch. Pain, 2004, 111(3), 360-367.

[159] Kennedy, W. R.; Vanhove, G. F.; Lu, S. P.; Tobias, J.; Bley, K. R.; Walk, D.; Wendelschafer-Crabb, G.; Simone, D. A.; Selim, M. M. A randomized, controlled, open-label study of the long-term effects of NGX-4010, a high-concentration capsaicin patch, on epidermal nerve fiber density and sensory function in healthy volunteers. $J$. Pain, 2010, $11(6), 579-587$.

[160] Oszlács, O.; Sántha, P.; Jancsó, G. Long-lasting antinocicepttve and anti-inflammatory effects of N-oleoyldopamine, an endogenous vanilloid. Neuropeptides, 2009, 43(5), 413.

[161] Binshtok, A. M.; Gerner, P.; Oh, S. B.; Puopolo, M.; Suzuki, S.; Roberson, D. P.; Herbert, T.; Wang, C. F.; Kim, D.; Chung, G.; Mitani, A. A.; Wang, G. K.; Bean, B. P.; Woolf, C. J. Coapplication of lidocaine and the permanently charged sodium channel blocker QX-314 produces a long-lasting nociceptive blockade in rodents. Anesthesiology, 2009, 111(1), 127-137.

[162] Kim, H. Y.; Kim, K.; Li, H. Y.; Chung, G.; Park, C. K.; Kim, J. S.; Jung, S. J.; Lee, M. K.; Ahn, D. K.; Hwang, S. J.; Kang, Y.; Binshtok, A. M.; Bean, B. P.; Woolf, C. J.; Oh, S. B. Selectively targeting pain in the trigeminal system. Pain, 2010, 150(1), 29-40. 